\title{
ZA BOLŠE RAZUMEVANJE TRANSFORMACIJSKE PARADIGME IN TRANSFORMACIJE OBOROŽENIH SIL
}

\author{
FOR BETTER UNDERSTANDING \\ OF TRANSFORMATIONAL PARADIGM \\ AND TRANSFORMATION OF ARMED FORCES
}

Povzetek V prispevku predstavljamo pojav transformacije in njene paradigme ter transformacije na obrambno-vojaškem področju. Najprej se lotevamo mejnih pojmov in zatem opredelimo transformacijo, njeno paradigmo in proces. Pri tem zajamemo izraze konsolidacija, konverzija, modernizacija, preoblikovanje, prestrukturiranje, reforma in reorganizacija, nadalje revolucijo na vojaškem področju in reinženiring ter posebej preobrazbo in transformacijo. Izhajamo iz dejstva, da se ti pojavi spreminjanja po koncu hladne vojne $\mathrm{v}$ različnih strokovnih in znanstvenih virih ter obrambno-vojaški praksi opisujejo z izrazi, ki so lahko sinonimi za opis enakih pojavov, večkrat pa so uporabljeni za opis povsem različnih, čeprav so si na prvi pogled precej podobni. $\mathrm{V}$ razpravi nas zanima, ali je transformacijska paradigma hibrid, katere so stične točke z revolucionarno in evolucijsko paradigmo ter kam jo umestiti. K temu dodajamo ugotovitve in stališča o primerjavi revolucij na vojaškem področju in $\mathrm{v}$ transformaciji. Vse za boljše razumevanje transformacijske paradigme in transformacije oboroženih sil, tako v nacionalnem kot širšem okolju. Treba je namreč priznati, da sta transformacijska paradigma in njena filozofija še nedodelani in premalo raziskani ter preizkušeni v praksi, čeprav ravno na obrambno-vojaškem področju zasledimo pomembne korake.

Ključne

Transformacija, transformacijska paradigma, transformacijski proces, tranzicija, besede revolucija na področju vojaških zadev.

Abstract The article presents the phenomenon of transformation and its paradigm as well as the transformation in the fields of defence and the military. First, we address border concepts and later define the transformation process and its paradigm with the terms such as consolidation, conversion, modernization, modification, restructuring, reform and reorganization, further on revolution in the military field and re-engineering, and particularly alteration and transformation. In doing so, we procees from the fact that at the end of the Cold War these phenomena of changing have been described 
in a variety of technical and scientific resources, as well as the defense and military practice with the terms that may be synonymous in describing the same phenomena, but are often used to describe completely different ones, although seeming similar at first. In the debate, we are interested in whether the transformational paradigm is a hybrid; which are the common points of the revolutionary and evolutionary paradigm, and where to place it. Additionally, we provide the findings and observations on the comparison of revolutions in the military sphere and the transformation, all with the aim to enable better understanding of the transformative paradigms and transformation of the armed forces, both nationally and wider. It is important to recognise that the transformational paradigm and its philosophy are still incomplete and insufficiently researched and tested in practice, although important steps have been noted just in the defence and military fields.

\section{Key words Transformation, transformational paradigm, transformational process, transition,} revolution in military affairs.

Uvod Skoraj petdeset let prejšnjega stoletja so velike spremembe, ki jih je prinašal razvoj tehnike in tehnologije vojaškega delovanja, poimenovali z vojaškimi revolucijami ali revolucijami v vojaških zadevah (angl. Military Revolution; Revolution in Military Affairs) (Rogers, 1995, Parker, 1996). S temi revolucijami so označevali hitro in globalno spremembo ključnega nosilca v tehniki ali tehnologiji vojaškega delovanja, vse do pojava informacijske dobe. $\mathrm{V}$ njej pa so informacije kot tako imenovane mehke sestavine vedno bolj nadomeščale vlogo pomembnih delov trdih vojaških sistemov in tako prevzemale vlogo ključnega nosilca (Alberts, 2003; Alberts in drugi, 2004). Tako je informacijska doba, čeprav tudi v njej srečamo pojmovanje »doba informacijske in digitalne revolucije«, omajala predstavo o revolucijah na vojaškem področju in o revolucionarni paradigmi nasploh. Ta preobrat se je zgodil kmalu po razpadu bipolarne delitve sveta in je do takrat prevladujoče mehanizme uravnoteženja moči povsem spremenil ter jim dal drugačne uteži. Obenem so oživljala spoznanja (Potts in Thackray, 2005; Binnedijk in Kugler, 2006) o tem, da se globalno spreminjanje na obrambno-vojaškem področju poleg hitrega in radikalnega spreminjanja, imenovanega revolucija, lahko dogaja tudi drugače. Odgovor je bil $\mathrm{v}$ transformaciji oziroma preobrazbi in ugotovitvi, da se v naravnem razvoju in tehničnih procesih dogajajo številne temeljite spremembe, ki niso povezane $\mathrm{z}$ nasilnim spreminjanjem in poimenovane kot revolucije.

Pri opazovanju in proučevanju transformacije s stališča obramboslovne znanstvene presoje se zastavlja vprašanje, ali je transformacija res vsebinsko nov pristop ali zgolj modna muha ali celo samo novo poimenovanje za že znane procese spreminjanja obrambno-vojaške organiziranosti. Zato se bomo v nadaljevanju poleg opredelitve in primerjave pojmov lotili še razločevanja med evolucijskimi in revolucijskimi spremembami. To je v zadnjem času zelo priljubljena raziskovalna, politična pa tudi publicistična tema, ki se nanaša na vprašanje, ali je temeljito spreminjanje $\mathrm{v}$ informacijski dobi mogoče doseči z revolucionarno paradigmo in ali je ta sploh sprejemljiva in uresničljiva. Vse to pa proučevanje transformacije vodi k vprašanjem širše družbene preobrazbe v razmerah globalizirane družbe in informatizacije. 
V raziskavi in razpravah izhajamo iz hipoteze, da se pojem in proces transformacije razlikujeta od tranzicijskih procesov ter z njimi povezanih pojmov preoblikovanje, reorganizacija, prestrukturiranje in reforma. V dilemi, ali uporabiti poslovenjen tuj izraz ali slovenski ustreznici preoblikovanje oziroma preobrazba, se odločamo za transformacijo.

\section{OPREDELITVE IN PRIMERJAVA MEJNIH POJMOV}

V slovenskem jeziku in praksi imamo vrsto izrazov za spreminjanje organizacij, ki so se bolj ali manj uveljavili tudi pri spreminjanju obrambno-vojaške organiziranosti. Opazni med njimi so konsolidacija, konverzija, modernizacija, preoblikovanje, prestrukturiranje, reforma in reorganizacija. Tem je treba dodati še štiri, in sicer so to revolucija $\mathrm{v}$ vojaških zadevah in reinženiring na eni strani ter preobrazba, ki je sopomenka za izraz transformacija, na drugi strani. Teh štirih izrazov glede na našo obravnavo ne bomo uvrščali v mejne, čeprav spadajo v pojmovno raznolikost, ki jo pojasnjujemo v nadaljevanju. Dodajamo različno uporabo nekaterih slovenskih izrazov v tujih jezikih oziroma njihovo prevajanje, kar je opazno zlasti v prispevkih in delih slovenskih avtorjev, objavljenih v tujini. Vse to kaže na slovensko posebnost ali težavo ob dejstvu, da je večina slovarjev, ki v drugih jezikih pojasnjujejo slovenske izraze s tega področja, v Sloveniji izdana v novem tisočletju.

\subsection{Pojmovna raznolikost}

Konsolidacija: Izraz konsolidacija po SSKJ (SAZU, 2000, str. 427) pomeni utrditev, okrepitev in se uporablja, ko gre za notranjo konsolidacijo, na primer države ali položaja. Izraz vojaški organizaciji ni tuj, saj se z njim srečuje praktično po vsaki vojaški akciji ali operaciji in ga opredeljuje tudi Vojaška doktrina (Furlan in drugi, 2006, str. 96). V praksi obrambno-vojaških sprememb pa so bile s konsolidacijo označene tudi aktivnosti za utrditev stanja v Slovenski vojski, ki so bile povezane s kadrovskimi zadevami in izboljšanjem profesionalizacije.

Konverzija: Konverzijo SSKJ (SAZU, 2000, str. 430) opredeljuje kot najpogosteje zavestno spremembo, ki vključuje lastnosti, oblike, vsebine in se lahko nanaša na spremembo državne ureditve ali mednarodnih odnosov, pa tudi druge vrste sprememb (ekonomske, filozofske, finančne, fizikalne, fiziološke, kemične in druge), Verbinc (1978, str. 116) pa jo označuje kot spreobrnitev, preureditev, pretvorbo.

Obrambno-vojaška konverzija je na znanstvenem področju v Sloveniji dobro raziskana in obravnavana $\mathrm{V}$ številnih prispevkih, najpogosteje se povezuje $\mathrm{Z}$ obrambno-vojaškim prestrukturiranjem. Jelušič (2002b, str. 149) pravi, da je obrambna konverzija oznaka za proces preureditve družbe po oboroženem spopadu. Od šestdesetih let prejšnjega stoletja pa so izraz uporabljali tudi za razlago koncepta krčenja obrambnih sektorjev in razorožitev v različnih državah. Procesi obrambne konverzije potekajo na različnih področjih, najpomembnejša pa so: (1) demobilizacija in krčenje števila osebja; (2) razoroževanje, kar povzroči tudi preusmeritev proizvodnih sredstev iz vojaške v civilno sfero ter uporabo teh sredstev 
v civilne namene; (3) ekonomske, psihološke, kulturne in politične spremembe, ki se pojavljajo v družbah zaradi zmanjševanja vojaških prizadevanj (prav tam, str. 151-165). K slednjim je treba dodati tudi konverzijo vojaških objektov, ki ima prav tako vrsto dimenzij, od urbanistične in arhitekturne do okoljske idr. (Prebilič, 2002, str. 188-189). Vse navedeno pa ima tudi posebno sociološko dimenzijo (prav tam; Selby in Jelušič, 1999).

Izraz se v slovenski obrambno-vojaški praksi po osamosvojitvi ni uveljavil. To bi lahko pripisovali tudi značilnostim sprememb, ki so se dogajale v Sloveniji in so bile drugačne kot v državah z intenzivnejšimi procesi demobilizacije, razoroževanja in demilitarizacije. Vzrok je lahko tudi v tem, da so vsaj na začetku nekateri procesi konverzije v Sloveniji potekali brez zgledovanja po mednarodnem okolju ali brez upoštevanja obrambne stroke, ki je pojav konverzije na veliko raziskovala in izraz uporabljala. Navedeno velja tudi za konverzijo vojaških objektov in vojaške industrije v Sloveniji, kjer značilnosti teh sprememb, kljub manjši intenzivnosti, vendarle niso bile drugačne kot v drugih državah ${ }^{1}$. Ugotavljamo, da z zmanjšanjem ali končanjem glavnih procesov in sprememb, povezanih $\mathrm{z}$ razorožitvijo, demilitarizacijo in demobilizacijo po koncu hladne vojne, v strokovnem prostoru ugasne tudi pojavljanje izraza konverzija. Gotovo tudi zaradi pojava novih in tekmovalnih izrazov.

Modernizacija: Izraz modernizacija se najpogosteje uporablja $\mathrm{V}$ povezavi $\mathrm{z}$ opremljanjem z najnovejšimi tehničnimi in strokovnimi pridobitvami (SAZU, 2000, str. 566). V vojskah modernizacija pomeni posodobitev vojaške opreme, bodisi z uvajanjem nove bodisi posodabljanjem obstoječe, in tehnoloških procesov oziroma delovanja.

V Sloveniji se v dolgoročnih in drugih razvojnih dokumentih obrambnega sistema in vojske izraz modernizacija najpogosteje uporablja pri opredelitvah opremljanja ter skupaj s izrazom reorganizacija oziroma preoblikovanje in transformacija. Iz tega sklepamo, da je modernizacija zastopana $\mathrm{v}$ številnih procesih oziroma oblikah spreminjanja obrambno-vojaške organiziranosti ali pa nastopa kot samostojna razvojna sprememba. Pri prevajanju slovenskega izraza v mednarodnem okolju ne opazimo posebnosti.

Preoblikovanje: SSKJ (SAZU, 2000, str. 1006) izraz preoblikovati opisuje kot dati čemu drugačno obliko in preoblikovati se, kot dobiti drugačne značilnosti, preoblikovanje pa kot postopek, v katerem se te spremembe dogajajo.

V Sloveniji se $\mathrm{v}$ razvojnih ter strateških obrambno-vojaških dokumentih najpogosteje uporablja prav izraz preoblikovanje Slovenske vojske. Izraz prevladuje predvsem v letih od 1999 do 2009, medtem ko Resolucija o splošnem dolgoročnem programu razvoja in opremljanja Slovenske vojske do 2025 iz leta 2010 namesto preoblikovanja nedvoumno opredeljuje transformacijo kot glavni proces sprememb. Izpostavimo še, da se izraz preoblikovanje v Sloveniji uporablja v ožjem in širšem

1 O tem tudi v Kopač (2006) ter Jelušič in Kopač (2006). 
pomenu. V ožjem pomenu za prikazovanje sprememb, ki prinašajo neko novo obliko, bodisi v strukturi bodisi v zmogljivostih ali celo dejavnostih, kot na primer pri izobraževanju in usposabljanju. Pri tem zasledimo tudi enačenje preoblikovanja z reorganizacijo, ne le v praksi, temveč tudi v strokovnih delih. V širšem smislu so z izrazom preoblikovanje zajete spremembe, pri katerih je jasno, da ne gre zgolj za drugačno obliko sprememb ali reorganizacijo, ampak je mišljena prenova ali celo preobrazba. Dodajmo, da je izraz preoblikovanje tisti, ki v Sloveniji označuje spremembe v obdobju profesionalizacije in pridruževanja Natu in EU oziroma se pretežno uporablja zanje. Za pojasnjevanje v tujini se je izraz preoblikovanje prevajal $\mathrm{v}$ defence and force restructuring (Manigart in Jelušič, 2001) v uradnih dokumentih pa $\mathrm{v}$ reorganization in po letu 2005 bolj ustrezno v transformation.

Prestrukturiranje: Izraz se po SSKJ (SAZU, 2000, str. 1023) uporablja za spremembe strukture organizacije ali prestrukturiranje sistemov. V tem kontekstu se je najpogosteje uporabljal tudi na obrambno-vojaškem področju pri opisovanju spreminjanja formacijske sestave poveljstev in enot ali strukture cele vojske oziroma obrambnega sistema. Slovar Univerze Cambridge opisuje izraz restructure kot organizirati podjetje, posel ali sistem na nov način, da bi bil učinkovitejši (CALD, 2008, str. 1218). Nekateri avtorji spremembe, povezane s prestrukturiranjem, zlasti v gospodarstvu, enačijo z reorganizacijo (Možina in drugi, 1994). Spet drugi pa prestrukturiranje oboroženih sil razumemo širše ter ga povezujejo z obrambnimi reformami (Grizold, 2005, str. 23) ali v posebnem konceptu sprememb, povezanih s konverzijo (Jelušič 2002b, str. 145-158). Obrambno prestrukturiranje in konverzija sta namreč zaznamovala desetletje po koncu hladne vojne, ko je obenem postalo tudi jasno, da samo s prestrukturiranjem ni mogoče doseči vseh potrebnih sprememb.

Reforma: Izraz reforma se po SSKJ (SAZU, 2000, str. 1153) uporablja za označevanje sprememb in spreminjanje sistema oziroma ureditve česa ali vsebine česa. Izraz reformirati pa se uporablja za spremeniti sistem, ureditev česa, reformirati organizacijo, nauk ali vero ipd. Slovar tujk (Verbinc, 1978, str. 603) francosko besedo reforme povezuje z izboljšanjem in popraviti, latinsko besedo reformare pa s preoblikovanjem.

Izraz je v mednarodnem okolju dobro uveljavljen in se uporablja v zelo širokem kontekstu reformnih prizadevanj. Obrambna reforma je definirana kot usklajen sklop aktivnosti, namenjenih izboljšanju učinkovitosti obrambnih sil (Law, 2009). Obsega proces, v katerem vlada in pristojno ministrstvo pregledata vlogo in cilje obrambnih sil in ministrstva ter jih konceptualno usmerita $\mathrm{v}$ doseganje sposobnosti za odziv na prevladujoča tveganja in ogrožanja v srednje- in dolgoročnem obdobju, zanje oblikujeta ustrezne programe in načrte ter zagotovita njihovo uveljavitev in nadzor nad njimi (prav tam).

Slovenska obrambno-vojaška praksa uporablja reformo pretežno za splošno označevanje sprememb ali izboljšav, in sicer kot samostojen izraz ali v povezavi z drugimi, zlasti z reorganizacijo in preoblikovanjem (Jelušič, 2002a in 2005; Kožar, 
2007). Ker je tujka poslovenjena in široko sprejeta, pri prevajanju slovenske besede in tolmačenju $\mathrm{v}$ tujem jeziku ni razhajanj. V mednarodnem okolju so obrambne reforme v strokovnih virih in praksi zelo široko zastopane.

Reorganizacija: SSKJ (SAZU, 2002, str. 1159) pojasnjuje reorganizacijo kot glagolnik od reorganizirati, reorganizirati pa kot na novo, drugače organizirati delo oziroma opraviti reorganizacijo. Slovar tujk (Verbinc, 1978, str. 613) angleški izraz reorganize pojasnjuje kot preurediti, reorganize organization pa kot preureditev organizacije. V organizacijski teoriji je reorganizacija (preosnova, preureditev, preustroj) proces spreminjanja organizacije in vzpostavljanja novih razmerij in struktur (Lipovec, 1987, str. 35). Nekateri avtorji načrtno spreminjanje organizacije definirajo kot organizacijski razvoj, za katerega sta značilna spreminjanje in inoviranje organizacije (Rozman in drugi, 1993, str. 190). Pri tem s spreminjanjem organizacije razumejo uveljavljanje zamisli, ki že obstajajo, medtem ko z inoviranjem razumejo uveljavljanje novih, povsem na novo razvitih zamisli.

V slovenski obrambno-vojaški praksi je izraz pogosto uporabljen, velikokrat se uporablja tudi kot sopomenka za prestrukturiranje in prevladuje v praksi sprememb Slovenske vojske v prvem desetletju njenega razvoja. Menimo, da je izraz reorganizacija širši, saj vključuje širše polje sprememb, ne le sprememb v strukturi, temveč tudi v organiziranju in delovanju (Šteiner, 1998).

Revolucija v vojaških zadevah: Definicija revolucije v vojaških zadevah (angl. Revolution in Military Affairs - RMA) označuje glavne spremembe $\mathrm{v}$ naravi bojevanja $\mathrm{z}$ inovativnimi aplikacijami novih tehnologij, ki v povezavi z dramatičnimi spremembami $\mathrm{v}$ vojaški doktrini ter $\mathrm{z}$ operativnimi in organizacijskimi koncepti v temeljih spreminjajo značilnosti in izvajanje vojaških operacij. Vključuje tri vidike: tehnološkega, organizacijskega in konceptualnega (Marshall v Ibrügger, 1998; Metz in Kievit,1995, str. 3). RMA prisega na revolucionarno paradigmo. Po Handleyu (1999, str. xxi in 8-9) vključuje spremembe v značaju in načinu bojevanja, ki krčijo bistvene kompetence nekega dominantnega nosilca oziroma oblikujejo nove bistvene kompetence v neki novi dimenziji bojevanja ali pa povzročajo oboje. Dodatno se bomo terminološke obravnave dotaknili še pri razpravi o revolucijah na vojaškem področju.

Reinženiring: Izraz reinženiring se v slovenskem prostoru pojavlja v organizacijskih teorijah in študijah kot oznaka za posebno vrsto sprememb, predvsem v podjetjih. Več avtorjev reinženiring pojmuje kot novo organizacijsko revolucijo podjetij, ki temelji na tem, da je treba staro organizacijo in njena načela preprosto zbrisati, ukiniti in začeti znova. Pri tem izhaja iz procesnega pogleda na organizacijo in prisega na teorijo poslovne revolucije (Hammer in Champy, 1993). Tudi Kaplan in Norton (2001, str. 377) omenjata, da gre pri reinženiringu podjetja za diskontinuiteto izboljšav procesov v okoliščinah, ko ti procesi ne vodijo več k rezultatom. Nekateri avtorji (Kovač v Rozman in drugi, 1999) pri obravnavi sodobnih oblik in pristopov organiziranja podjetij poleg izraza reinženiring uporabljajo tudi izraz inoviranje, kar lahko razumemo kot oddaljevanje od modela poslovne revolucije. 
V slovenskem obrambno-vojaškem spreminjanju organiziranosti se izraz kljub poskusom (Podbregar, 2011) ni uveljavil. Tudi poskusi procesnih analiz in iz tega izhajajočih sprememb delovanja $\mathrm{v}$ slovenskem primeru niso dali pričakovanih rezultatov.

Preobrazba: SSKJ (SAZU, 2000, str. 1007) preobrazbo pojasnjuje kot pojav, da dobi kdo ali kaj drugačno vsebino, obliko v povezavi z družbeno, politično preobrazbo; duševno ali idejno preobrazbo. Glagol preobraziti pa kot narediti, povzročiti, da dobi kdo ali kaj drugačno vsebino, obliko, kot primere pa navaja gospodarsko preobrazbo države, socialistično preobrazbo vasi, notranjo preobrazbo človeka, preobrazbo amaterskega gledališča v poklicno idr. ${ }^{2}$

V Sloveniji se izraz preobrazba skupaj s preoblikovanjem pojavlja kot sopomenka za transformacijo. V primerjavi s preoblikovanjem pa se beseda ni uveljavila ${ }^{3}$.

Transformacija: SSKJ (SAZU, 2000, str. 1414) izraz transformacija pojasnjuje kot preoblikovanje, preobrazbo, na primer družbenih odnosov, in kot spremembo, pretvorbo, na primer v elektroniki in matematiki. Transformirati pa kot preoblikovati, preobraziti, na primer organizacijo, mednarodne odnose, oziroma kot spremeniti, pretvoriti, na primer transformacija živalskih vrst ali transformacija energije. Veliki slovar tujk (Tavzes in Adlešič, 2002, str. 1176) izraz transformacija pojasnjuje kot pretvorbo, preoblikovanje oziroma kot preslikavo in preobrazbo, transformirati (iz lat. transformare - preoblikovati) pa kot preoblikovati, spremeniti obliko, videz, značaj oziroma v fiziki spremeniti, pretvoriti. Iz navedenega lahko sklenemo, da v slovenskem okolju izraz transformacija kot glagolnik veže glagole transformirati preobraziti - preoblikovati. Verbinčev Slovar tujk (1978, str. 723) transformizem pojasnjuje kot razvojno teorijo (na primer pri spreminjanju živalskih in rastlinskih vrst $)^{4}$. Slovar Univerze v Cambridgeu izraz transform pojasnjuje kot celovito spreminjanje oblike in vsebine in to povezuje z organizacijo, ki se bo transformirala. Izraz transformation pa pojasnjuje kot celovito spremembo videza oziroma pojava ali značaja oziroma vsebin, posebno izboljšav (CALD, 2008, str. 1548).

Poslovenjenje angleškega izraza transformation je staro toliko kot pojav transformacijske paradigme na svetovnem prizorišču ${ }^{5}$. Izraz navaja SSKJ (SAZU 1994), prav tako pa tudi Besedišče slovenskega jezika z oblikoslovnimi podatki (Žnidaršič, 1998). Ker se v slovenskih slovarjih k izrazu transformacija dodajata izraza preoblikovanje in preobrazba, lahko sklepamo, da gre za sopomenke. Na obrambno-vojaškem področju pa je izraz prevzet iz tujine in se pojavlja od začetkov transformacijskega procesa in sprememb v Slovenski vojski.

\footnotetext{
2 V botaniki: preobrazba rastlinskih organov zaradi drugačnega načina prehrane; preobrazba listov; v zoologiji preobrazba živalskega organizma na razvojni stopnji med jajčecem in odraslo živaljo, preobrazba žuželk; popolna preobrazba, ki ima vse razvojne stopnje (prav tam).

3 Redko izjemo predstavlja Kožar (2007, str. 66-76), ko pojasnjuje preobražanje nemških oboroženih sil.

4 Enako v Tavzes in Adlešič (2002, str. 1176).

5 O tem tudi Švab in Berlogar (2013, str. 45).
} 
Sklenimo ta del predstavitve pojmovne raznolikosti v slovenskem obrambno-vojaškem prostoru še z ugotovitvijo, da Veliki slovar tujk (Tavzes in Adlešič, 2002) pojasnjuje izraze konsolidacija, konverzija, modernizacija, reforma, reorganizacija in transformacija, Vojaški slovar (Korošec, 2002) navaja reorganizacijo in modernizacijo, medtem ko dvojezični Slovensko-nemški vojaški slovar (SIB, 2010) vsebuje izraze konsolidacija, prenova, preoblikovanje, reforma, reorganizacija in transformacija.

\subsection{Nadaljnje razločevanje sprememb in izrazja}

Pri proučevanju pojmov za označevanje sprememb obrambno-vojaške organiziranosti velja upoštevati tudi njihovo razločevanje glede na to, ali gre za razvojne spremembe ali za spremembe, ki so globlje ali temeljitejše oziroma radikalnejše. Govorimo o razločevanju med evolucijskimi in revolucijskimi spremembami. Pri evolucijskih so v ospredju spremembe, ki nastanejo kot posledica razvoja oziroma razvojnih prizadevanj, za revolucijsko spreminjanje pa je značilna hitra, radikalna in praviloma na nasilju ali sili temelječa sprememba oziroma povsem nova tehnološka sprememba. Po tem izhodišču lahko razločujemo tudi teorije in paradigme.

V dosedanji obravnavi predstavljene izraze, ki označujejo spremembe na obrambno-vojaškem področju, bi po prej navedenem lahko razvrstili v dve skupini: razvojne in revolucionarne. Med revolucionarne $\mathrm{z}$ lahkoto uvrstimo revolucijo v vojaških zadevah in reinženiring, ki se tudi sama označujeta kot revolucionarna ${ }^{6}$. Izrazi konverzija, konsolidacija, modernizacija, preoblikovanje, prestrukturiranje, reforma in reorganizacija so pretežno uporabljeni v razvojnem kontekstu. Pri izrazih preobrazba in transformacija pa smo pred dilemo, ali ju uvrstiti med razvojne ali revolucionarne, o čemer bomo še razpravljali.

Poleg tega v slovenskem jeziku naletimo na težave, saj so bili izrazi, kot so obrambna ter vojaška reforma, obrambno prestrukturiranje, konverzija, reorganizacija vojske, pa tudi preoblikovanje, uporabljeni v besedilih in kontekstih, ki zadevajo prilagajanje obrambne in vojaške organiziranosti v obdobju družbene in obrambno-varnostne tranzicije. Ob predstavitvi in primerjavi teh izrazov pa je očitno tudi, da so za naše potrebe preplitki, saj se nanašajo le na spremembo v organiziranosti.

Omenimo še izziv, ki ni zgolj pojmovni, temveč tudi znanstveni in se nanaša na vprašanja, ali je temeljito spreminjanje $\mathrm{v}$ informacijski dobi mogoče doseči $\mathrm{z}$ revolucionarno paradigmo oziroma ali je ta sploh sprejemljiva in uresničljiva. Je pa zamisel revolucionarne paradigme, ki bi mehke elemente sodobnih sistemov, vključno $\mathrm{z}$ informacijskimi, preprosto odstranila ali izbrisala in nadomestila $\mathrm{z}$ novimi, ustreznimi, zelo mamljiva. V nadaljevanju bomo prikazovali tudi razvojno pot izrazov vojaška revolucija in revolucija v vojaških zadevah, ki sta za svojo uveljavitev potrebovala dobrega pol stoletja. Zapišimo, da sta se sicer uveljavila,

\footnotetext{
" Pri tem je seveda treba ustrezno razumeti vpliv nasilja oziroma sile v radikalni spremembi, ki ni vedno enaka nasilju ali sili $v$ družbenih revolucijah. Primer je zmanjševanje služb vojaških pilotov zaradi pojava brezpilotnih letalnikov in transformacije njihovega poklica.
} 
nista pa preživela zaradi narave sprememb časa, v katerem smo, ker sta prisegala na revolucionarno paradigmo oziroma je kot sprejemljivejša prevladala transformacijska paradigma.

V slovenskem primeru pa smo še pred eno dilemo, ali uporabiti poslovenjen izraz, kot je bilo to na primer pri besedi revolucija, ali pa uporabljati slovenski besedi preoblikovanje oziroma preobrazba. Preoblikovanje ne ustreza že zato, ker ne želimo izraza, ki bi označeval spremembo, ki prinaša zgolj drugačno obliko oziroma prezre vsebinski del sprememb. Preobrazba sicer pokaže na spremembo oblike in obenem drugačno vsebino, zato $\mathrm{v}$ tem pogledu ustreza. A je preobrazba povsem neuveljavljena $\mathrm{v}$ slovenski obrambno-vojaški praksi. Z gotovostjo lahko tudi zapišemo, da je precej negativno označena, kar lahko vpliva na sprejemanje in razumevanje izraza ter ne nazadnje na motivacijo in sinergijo pri uresničevanju njegove vsebine. Vendar težavo obeh vidimo $\mathrm{v}$ tem, da bi s prevodom $\mathrm{v}$ tuj jezik in tolmačenjem $\mathrm{v}$ mednarodnem okolju ponovno prevečkrat zašli v pojmovanja, ki ne bi bila odraz vsebine in razumevanja, ki jih želimo predstaviti. Takšne primere srečamo tudi v dosedanji praksi, ko se izraz preoblikovanje uporablja v pomenu iz preteklosti, čeprav želimo izpostaviti transformacijske spremembe, in obratno, ko se omenja transformacija zgolj za reorganizacijske spremembe tranzicijskega tipa.

Ker gre pri transformaciji za razmeroma novo organizacijsko paradigmo, menimo, da je pri odločanju med sopomenkama preobrazba in transformacija smiselno uporabiti tuje poimenovanje. Podobno kot smo to v preteklosti naredili pri revoluciji in evoluciji. Takšna uporaba bo tudi $\mathrm{v}$ širšem okolju pripomogla $\mathrm{k}$ boljšemu in enotnejšemu razumevanju. Obenem pa se bomo lažje izognili težavam pri prevajanju. Z manj težavami bomo lahko tudi pojasnjevali, da je obdobje spreminjanja oblik preseženo in smo pred obdobjem preobrazbe, ki jo pojmujemo tudi na semantično prepoznaven način.

K navedenim razmišljanjem dodajmo še, da je na vprašanje, ali med tranzicijo in transformacijo obstajajo povezave in razlike, treba odgovoriti pritrdilno. Tranzicijske spremembe so usmerjene v prilagajanje, transformacijske pa v preobrazbo. Pri prvih gre za opuščanje starega in prehod v novo, pri drugih pa za vzpostavljanje novega in prenos kompetenc na novega nosilca. S tranzicijo naj bi vzpostavili neko primerljivo stanje ali dosegli znane standarde, po drugi strani pa se pri transformaciji poleg novih oblik delovanja in organiziranosti vzpostavljajo druge, raznovrstne kakovostne spremembe in se kot del izgradnje sistemov oblikujejo nove. Sta pa tranzicija in transformacija povezani, saj so pred transformacijo praviloma tranzicijsko obdobje in tranzicijske spremembe. 


\section{OPREDELITEV TRANSFORMACIJE, TRANSFORMACIJSKE PARADIGME IN TRANSFORMACIJSKEGA PROCESA}

\subsection{Opredelitev transformacije v slovenskem okolju}

V slovenski Vojaški doktrini je ta opredelitev:

Pojmovanje transformacije vojske je povezano $z$ redefiniranjem pristopov $k$ vojskovanju, ki so nastali s premikom iz industrijskega $v$ informacijsko obdobje, kjer predvidljive grožnje iz obdobja hladne vojne vedno bolj nadomeščajo nepredvidljive asimetrične in nekonvencionalne grožnje. To zahteva prenovo vojske in njene vloge ter njeno temeljito spremembo oziroma preoblikovanje (Furlan in drugi, 2006, str. 105).

Brožič (2013, str. 4) obravnava izraz transformacija vojaških zmogljivosti in ga opredeljuje kot kontinuiran in proaktiven proces razvijanja ter integriranja inovativnih zasnov, doktrin in zmogljivosti, z namenom izboljšati učinkovitost ter interoperabilnost Nata in partnerskih držav. Pri tem izpostavlja, da ne gre le za nove oborožitvene sisteme in modernejšo opremo, temveč tudi za nov pristop, s katerim se bodo bolje opravljali poslanstvo in odločanje ter uporabljale prednosti, ki jih prinaša nova tehnologija za razvoj zmogljivosti.

$\mathrm{K}$ že predstavljenim opredelitvam transformacije in argumentom za uporabo izraza v slovenskem prostoru tu dodajamo še mojo opredelitev kot rezultat dosedanjega raziskovanja in proučevanja: Transformacija na obrambno-vojaškem področju je premišljeno, načrtno in na sinergiji temelječe nenasilno spreminjanje, ki vodi $v$ preobrazbo s spremenjenim poslanstvom in nalogami, novimi organizacijskimi strukturami in zmogljivostmi ter posledično $\mathrm{z}$ novo kvaliteto $\mathrm{v}$ socialnem in funkcionalnem imperativu.

\subsection{Opredelitve transformacije $v$ mednarodnem okolju}

Transformacijo kot nov izraz v Zavezništvu uradno poznamo od vrha v Pragi leta 2002, ko je bil začetek transformacije tudi uradno potrjen (Nato Handbook, 2006, str. 20), zatem pa je bilo oblikovano tudi Zavezniško poveljstvo za transformacijo (ACT). V Natu obstaja več opredelitev transformacije, kar kaže tudi na razvojno pot pojava in njegovih opredelitev $\mathrm{v}$ tem okolju.

V publikaciji Examine Nato's Transformation (Nato, 2005, str. 8-9) med drugim najdemo definicijo Garstka, ki navaja, da je transformacija trajna, namensko usmerjena celovita sprememba, uveljavljena skladno s strateškimi cilji za ustvarjanje ali ohranjanje konkurenčnih prednosti oziroma kot odziv na prednosti, ki jih ima sedanji ali novi nasprotnik. Zatem dodaja, da se konkurenčne prednosti dosegajo pretežno z izkoriščanjem novih ali nastajajočih tehnologij, kar pogosto zahteva spremembe $\mathrm{v}$ organizaciji, procesih ali ljudeh.

Smith (2006, str. 4) pravi, da vojaška transformacija pomeni več kot le postopno reformo ali pridobitev novih oborožitvenih sistemov. Obsega pospešeno tehnološko 
modernizacijo, doktrinarne reforme, preusmeritev in reorganizacijo sil in struktur, kulturo za spremembe ter pripravljenost sprejeti tveganje.

Največ različnih opredelitev transformacije glede na raznolikost obravnav je v ZDA. Hundley (1999, str. 1) navaja, da je ameriški pristop k transformaciji v začetnem obdobju vključeval razvoj več vizij za prihodnost in s tem povezanega bojevanja, oblikovanje številnih vojaških laboratorijev in centrov za prihodnje bojevanje, vključno s simulacijami in razvojem vojnih iger, eksperimenti ter novimi organizacijskimi rešitvami. Vse to je bilo pospremljeno s številnimi tehnološkimi produkti ali sistemi, vključujoč naprave za natančni ogenj, informacijsko bojevanje, povezane sistemske rešitve in robote, mrežno povezane sisteme in delovanje ter druge zmogljivosti, temelječe na digitalizaciji in nanotehnologiji, biotehnologiji ter drugih sodobnih materialih in rešitvah.

Binnedijk in njegovi sodelavci na washingtonski National Defense University (2002) v svojih delih prav tako ponujajo več opredelitev transformacije. Pri tem pravijo, da se v današnjem okolju transformacija uporablja za izražanje obsežnega procesa prilagajanja zahtevam in možnostim informacijske dobe. Transformacija se pogosto začne z uvajanjem novih tehnologij, vendar se ne konča s tem in lahko vodi k spremembam v vsej strukturi, pogosto se uresničuje na različne načine.

Jasper (2009, str. 2-3) pa izpostavlja, da po definiciji transformacija nima končnega stanja. Transformacijo opredeljuje kot nenehen proces, ki oblikuje značaj vojaških udeležencev in sodelovanja s kombinacijo tehnologij, organizacijskih struktur, inovativnih procesov in prilagoditve osebnega razvoja, kar vse vodi v nacionalne prednosti in ščiti pred asimetričnimi ranljivostmi.

Mandeles (2007, str. 6) v svoji opredelitvi poudarja odvisnost sprememb od tehnološkega napredka in povezave med vojaško revolucijo ter transformacijo. Je zagovornik tega, da je vojaška transformacija, podobna vojaški revoluciji.

Alberts (2003, str. vii) izpostavlja prilagoditveno naravo, ko navaja, da je transformacija proces prenove in prilagoditve okolju. Hitrost in napredek sta odvisna od narave subjektov transformacije, okolja in vodnikov oziroma nosilcev transformacije. Pri tem so pomembne vitalnost entitet ter njihove omejitve in sposobnosti za prilagoditve. Dodaja, da so spremembe in prilagodljivost osebja vedno bistvene sestavine transformacije.

Izpostaviti je treba še opredelitev Cebrowskega (Cebrowski v Alberts in Hayes, 2005, str. 30), ki pravi, da transformacija pomeni obravnavo skupnega razvoja konceptov, organizacije, procesov in tehnologij. Sprememba katerega koli izmed teh področij povzroči spremembe za vse. Transformacija pomeni ustvarjanje novih konkurenčnih področij in novih pristojnosti oziroma kompetenc. 
Knott (2004, str. 52-54) sicer ne navaja opredelitve transformacije. Kot zanimivost pa navajamo njegovo trditev, v kateri pravi, da transformacija usmerja intelektualne vizije v vojaške zmogljivosti, in dodaja, da mora intelektualizem delovati znotraj institucionalnega okvira. Izpostavlja, da transformacija, ki je rojena na intelektualni energiji, lahko uspeva le, če je ta znotraj institucionalnega okvira in vezana na sistem.

Dodajmo še najpogosteje citirano ameriško uradno definicijo transformacije kopenske vojske (izvirno Army Transformation) (DOD US, 2003; military.wikia. com). Ta je opredeljena kot koncept prihodnje modernizacije, ki vključuje nove koncepte, organizacijo in nove tehnologije. Pri tem je predvideno tudi preoblikovanje vojaške organizacijske strukture, tako da bo pripravljena za ves spekter delovanja. Ta prizadevanja vključujejo modernizacijo, modularno oblikovanje, kombinacijo med aktivnimi in rezervnimi sestavami ter model nabora sil za operacije.

Za primerjavo dodajmo nemško opredelitev (White Paper, 2006, str. 74-76), ki navaja, da sta najpomembnejša cilja transformacije izboljšanje in ohranjanje operativnih zmogljivosti Bundeswehra v spreminjajočem se okolju. Transformacija se dotika vseh vidikov oboroženih sil in ima varnostno-obrambne, družbene, tehnološke in predvsem inovativne ter človeške razsežnosti.

\subsection{Vidiki transformacije}

Iz predstavljenih opredelitev transformacije lahko prepoznamo tudi različne vidike in pristope k njenemu opredeljevanju. Ugotovimo, da so vidiki transformacije lahko: (a) konceptualni, (b) tehnološki, (c) procesni in (d) logistični. Konceptualni vidik se nanaša na miselne sestavine $\mathrm{v}$ obliki konceptov, teorij in inovacij, tehnološki vidik pa na tiste elemente, ki se v angleškem okolju označujejo s hardware in se nanašajo pretežno na tehnologije, zlasti na nove, med katerimi so najpomembnejše informacijske. Procesni vidik se nanaša na elemente, ki se dotikajo organiziranja in delovanja. Temu je treba dodati tudi strukturne elemente obrambno-vojaških organizacij. Logistični vidik je povezan z viri, predvsem s kadrovskimi, finančnimi in tudi časovnimi. K navedenemu je treba dodati še zmogljivosti, ki predstavljajo kombinacijo konceptov, organiziranosti in ljudi ter tehnologije, vse pa je usmerjeno v funkcionalno učinkovitost.

Ko obravnavamo vidike transformacije na obrambno-vojaškem področju, prav tako ugotovimo, da države k njej pristopajo različno, odvisno od svojih zmožnosti, sposobnosti in namenov ter ciljev. Nanjo vplivajo tudi politični dejavniki, vojaška kultura in ogrožanja.

Zato je k opisu vidikov transformacije treba dodati še Hammonda (Hammond v Neal in drugi, 2009, str. 2), ki pojasnjuje različno pojmovanje transformacije v odvisnosti od pristopa. Pri tem izpostavlja najmanj tri pojmovanja. Pri prvem gre pretežno za tehnološki vidik transformacije in vključuje spremembe pojavne oblike nekoga ali nečesa, kot primer pa navaja, da so z nakupom nove vojaške opreme države transformirale in modernizirale sile ter dosegle boljše zmogljivosti. 
Drugo pojmovanje je povezano $\mathrm{z}$ bolj poglobljenimi in bolj kompleksnimi spremembami, vključujoč reorganizacije in zmanjševanje obsega, doseganje povezljivosti procesov in doktrin, kar vse omogoča nadaljnjo transformacijo sil in se kaže v stanju, naravi ali funkcionalnosti oboroženih sil. S to transformacijo, ki ima več značilnosti konverzije, je veliko držav spremenilo nacionalne oborožene sile, da bi te postale moderne, mrežno orientirane in povezljive z drugimi državami Zavezništva. Tretje pojmovanje poleg omenjenega izpolnjuje tudi vse ključne elemente iz celovitih opredelitev transformacije (prav tam). Pri tem transformacija vključuje tudi spreminjanje narave in namena oboroženih sil ter njihove vloge v družbi, kar vodi tudi k spreminjanju njihovega socialnega in funkcionalnega imperativa. Dodajmo, da spreminjanje organizacij poteka $\mathrm{v}$ transformacijskem procesu.

\subsection{Transformacijska paradigma}

S transformacijsko paradigmo označujemo družbeno in vojaško preobrazbo vloge vojaške sile oziroma, kot pišeta Binnendijk in Kugler (2006, str. 10-13), opuščanje neo-Hobbesove filozofije in narave držav, ki kot primarni instrument uporabljajo vojaško silo. Gre za novo in še ne povsem uveljavljeno paradigmo sprememb, ki kaže težnjo po tem, da na obrambno-vojaškem področju postane nov primer spreminjanja njene organiziranosti. Transformacijska paradigma temelji na analizi modela nacionalnih vojsk in uporabe vojaške sile, njenih notranjih nasprotij in omejitev v času globalizacije ter na pojavih nadnacionalnih oziroma globalnih ogrožanj in kriz. Paradigma je torej globalna in nadnacionalna. Obenem intenzivno izpodriva in nadomešča paradigmo revolucije $\mathrm{v}$ vojaških zadevah. Zato se na obrambno-vojaškem področju kaže kot razumna alternativa za preobrazbo uporabe vojaške sile v globalizaciji. Transformacijska paradigma je zasnovana kot celostni pristop $\mathrm{k}$ dojemanju in spremembam v obrambno-vojaški sferi in celo več, usmerjena je $\mathrm{v}$ priseganje na nove organizacijske modele, ne le na obrambne sisteme, vojstvo in dejavnosti, temveč tudi na upravljavce, vključujoč politične določevalce, obrambno-vojaške strategije in vizije.

Izpostavljamo usmerjenost paradigme v preobrazbo nacionalnih obrambno-vojaških področij, pri čemer so obrambni sistemi in vojske deležni velikih sprememb, zanje pa je treba najti ne le politične, temveč tudi tehnološke in organizacijske rešitve (Binnendijk in Johnson, 2004). Poudarimo, da transformacija temelji na nenasilnem in domišljenem ter na znanju in prednostih informacijske družbe temelječem spreminjanju obrambno-vojaških struktur, organiziranosti in nalog ter, ne nazadnje, vloge vojske v družbi. Pravno področje je eden najpomembnejših vidikov transformacijskih sprememb, saj te potrebujejo legalni okvir in morajo biti legitimne. V tem pogledu se transformacijske spremembe pomembno razlikujejo od revolucionarnih, zlasti na družbenem področju.

Pri širjenju in uresničevanju transformacijske paradigme je pomemben pristop, $\mathrm{s}$ katerim široka dostopnost do védenja in spoznanj postaja eno izmed transformacijskih načel ter vzvod hitrejšega spremljanja in uresničevanja transformacijskih novosti. Navedeno vodi k povezovanju in zbiranju teoretičnih modelov in dobrih praks, 
obenem pa omogoča njihovo izmenjavo ter nadgradnje. To je pomembno tudi zato, ker se transformacijski procesi v nacionalnih okoljih uveljavljajo z različno hitrostjo in intenzivnostjo glede na stopnjo razvoja ter vpetost $\mathrm{v}$ skupne transformacijske procese $\mathrm{v}$ Zavezništvu.

\subsection{Transformacijski proces}

Transformacijski proces opredelimo kot med seboj povezane pojave in aktivnosti, ki se nanašajo na transformacijske spremembe oziroma vodijo k transformaciji. Natov priročnik (izvirno Nato Handbook) navaja, da gre pri transformacijskem procesu za proaktiven in inovativen proces razvoja ter integracije novih konceptov, doktrin, zmogljivosti in struktur, da bi se izboljšala povezljivost (2006, str. 20-21). Sprožajo ga praviloma transformacijske avtoritete s posebnimi transformacijskimi smernicami in cilji, ki jih želijo doseči. Transformacijske avtoritete skrbijo tudi za spremljanje procesa, ugotavljanje in analizo dosežkov, pa tudi za zbiranje, proučevanje in izmenjavo izkušenj.

Proces temelji na domišljenosti in medsebojni povezanosti ter zahteva intelektualno superiornost. Izpostavimo, da gre za dolgotrajen proces, v katerem imajo posamezne faze tudi tranzicijske značilnosti, ki vodijo k dolgoročnim transformacijskim ciljem. Proces vključuje širok seznam sprememb, ki naj bi nastale z uvajanjem novih tehnologij in gradnjo zmogljivosti sil, ter sprememb strukture sil, doktrin in standardov delovanja vojaških sil za zagotovitev sposobnosti za prihodnje poslanstvo, naloge in delovanje.

Zato je za uspešnost transformacijskega procesa pomembno oblikovanje vizij sprememb in konceptov zanje. Pri snovanju transformacijskega procesa se upoštevajo izhodišča za spremembe, njihovo dinamiko, priložnosti in izzive, ki jih prinašajo. Strateški dokumenti, kot so strateški pregledi obrambe oziroma dolgoročni razvojni dokumenti za obrambno-vojaške sisteme, politične resolucije in dolgoročne vizije, praviloma postavljajo cilje tudi za transformacijski proces.

Proces mora biti načrten in celovit, čeprav se velikokrat osredotoči prav na izbrana oziroma nišna področja ali zmogljivosti. Pri tem je zelo pomembno tudi, kakšna bo pot prihodnjih sprememb. Bo takšna, ki poteka od zgoraj navzdol in se spremembe začnejo pri najvišjih, ali bo potekala od spodaj navzgor? Sodoben pristop je predvsem domišljen in usklajeno poteka z obeh strani (Šteiner, 2013, str. 19). Ob tem je ključna tudi zagotovitev primerne usposobljenosti in voditeljstva za vodenje procesa. Čas za spremembe ter podpora zanje in sinergija naporov so pomembni pogoji za uspešne rezultate $\mathrm{v}$ procesu transformacije. Ko gre za spremembe in podporo zanje zunaj obrambno-vojaškega sistema, sta zelo pomembna tudi politična podpora in širše razumevanje transformacije. Prav tako sta pomembni tudi že omenjena vključitev v transformacijska omrežja in uporaba dosežkov transformacijskih študij, raziskav, eksperimentov in naučenih lekcij. 
$\mathrm{V}$ pojavnih vidikih in poteku transformacijskega procesa, kot jih opredeljuje Hammond, se kažejo tudi evolucijske značilnosti transformacije. Proces poteka skladno s spreminjanjem narave in namena obrambnih sistemov in vojsk, pa tudi z oblikovanjem novih ključnih nosilcev in zmogljivosti v njih. Zato pri opazovanju in spremljanju transformacijskega procesa opazimo različne pojavne oblike in razvojna obdobja. Ta se gibljejo od obdobij s pretežno tranzicijskimi spremembami proti obdobjem, v katerih prevladujejo transformacijske spremembe. Vendar se tudi transformirani sistemi še naprej spreminjajo in izboljšujejo. K temu je treba dodati vprašanje razvojnega stanja ali točke, v kateri se zgodi preusmeritev tranzicijskih sprememb v transformacijske. Dodajmo, da te preusmeritve ni mogoče izvesti zgolj deklarativno ali normativno, ampak morajo biti izpolnjeni nekateri pogoji v razvoju in kakovosti sistema, ki omogočajo prehod na višjo stopnjo zahtevnosti sprememb.

Proces transformacije prinaša na obrambno-vojaškem področju, tako v nacionalnih okoljih kot tudi v Zavezništvu, velika pričakovanja, pa tudi dvome. Ti se kažejo tudi kot strah pred hitrim izginjanjem nacionalnega ali celo klasičnega vojstva. Države si v obdobju transformacije postavljajo za cilj oblikovanje vojsk, ki so po obsegu manjše, a učinkovitejše, bolj profesionalne, sodobneje opremljene, povezljive ter sposobne uresničevati poslanstvo $\mathrm{v}$ širokem spektru nacionalnih in nadnacionalnih nalog.

Ko omenjamo vstopanje držav $\mathrm{v}$ transformacijske procese, je pomembno tudi, v kakšnih razmerah je mogoče uspešno opraviti spremembe, še zlasti, če vemo, da transformacija ne prisega na radikalno ali nasilno spreminjanje. To je toliko bolj aktualno $\mathrm{v}$ časih globalne gospodarske krize in recesije, ko so prizadete tako velike kot majhne države. Poleg tega so nacionalni obrambno-vojaški sistemi $\mathrm{v}$ tehnološkem pogledu tesno povezani z znanostjo in industrijo, če ne celo odvisni od njiju, zato je hitrost odvisna od tega razmerja in sposobnosti sledenja spremembam ter medsebojnemu prilagajanju. Zelo zanimiva je sprejemljivost transformacijskih sprememb tudi $\mathrm{z}$ vidika velikih in majhnih držav ter sposobnosti spreminjanja njihovih obrambno-vojaških sistemov. Tisto, kar je pri uresničevanju razvoja in sprememb za velike samoumevno, je za majhne velikokrat težko sprejemljivo, če ne celo neuresničljivo. In nasprotno, pri spremembah, ki jih majhni z lahkoto uresničijo, veliki potrebujejo posebne mehanizme in okoliščine, da jih sprejmejo in opravijo.

Sklenimo ta del obravnave $\mathrm{z}$ ugotovitvijo, da transformacije kot pojava oziroma transformacijske paradigme in transformacijskega procesa še ne pojmujemo enotno, saj je v različnih državah in organizacijah ter pristopih različno razumljena, odvisno tudi od vsebine sprememb.

Za dokončno uveljavitev transformacijske paradigme bodo nujni tudi globalno družbeno soglasje in temu ustrezne spremembe. Poleg tega pa bo s transformacijsko paradigmo treba najti odgovore na več vprašanj, na primer, kako preseči statično miselnost uravnoteženja moči in obrambe prostora. Ob tem je v Zavezništvu aktualno tudi vprašanje redefiniranja koncepta kolektivne obrambe glede na 
spremenjeno ogrožanje in odmik od klasične vojaške domene. Vendar je vse to le en pogled na preseganje uravnoteženja vojaških moči. Drugi je povezan z vprašanjem, kako se glede vloge in uporabe vojaških sil preusmeriti predvsem v izhode, namesto dosedanjih usmeritev $\mathrm{v}$ vhode in vlaganja.

V preteklosti so bile spremembe na področju obrambno-vojaške organiziranosti, zlasti tiste, ki so jih označevali kot revolucionarne, povezane s tehnološkim vidikom. Tehnološki vidik je v transformacijski paradigmi zelo pomemben in širok. Vključuje tudi tehnološko bazo in možnosti za njeno posodabljanje, predvsem informatizacijo in digitalizacijo, s tem pa tudi opuščanje ali odmiranje struktur, vojaškotehničnih sistemov in celo vojaškega delovanja. Zato se številni pristopi v transformacijskem procesu še vedno osredotočajo predvsem na to dimenzijo.

Eden najpomembnejših elementov transformacije je intelektualni - znanje, učenje in razumevanje. S tem pa smo tudi pred vprašanjem intelektualne preobrazbe obrambnovojaških sistemov in njihovih kadrovskih, izobraževalnih in razvojnih struktur.

\section{RAZPRAVA: TRANSFORMACIJSKA PARADIGMA KOT HIBRID}

Transformacijska paradigma je odziv na pojave sodobnega sveta, ki se, kot smo že omenili, po Binnendijku in Kuglerju poskuša odzivati na neokantovske kot tudi neo-Hobbesove značilnosti sveta in uporabo moči v njem. Izpostavimo, da ni zgolj obrambno-vojaška domena. Pri tem se transformacijska paradigma z združevanjem Kantovih in Hobbesovih pogledov kaže kot neke vrste hibrid. Smo torej pred paradigmo, ki je hibrid z možnostmi in vidiki več vrst?

Ponovimo ugotovitev, da so transformacijske spremembe na obrambno-vojaškem področju povezane s spremembami na drugih področjih. Ko jih opazujemo kot evolucijske, je pomembna tudi njihova soodvisnost. Pri tem ugotovimo, da s koncem bipolarnosti nastanejo spremenjene razmere, ki poleg političnega, ekonomskega in varnostnega obsegajo tudi druga področja (socialno, humanitarno). Hladna vojna se je končala zaradi sesutja komunističnega sistema, do tega pa je prišlo zaradi njegove ekonomske neprilagodljivosti.

Spoznanju ob koncu hladne vojne o nujnosti hitrejšega prilagajanja sta na vseh področjih sledila obdobje prilagajanja oziroma tranzicije ter iskanje odgovorov na nove paradigme. Pri tem tudi odgovorov na vprašanje, kako dolgo bodo nacionalne države še temelj človeških odnosov in družbene organiziranosti, ki je zrcalno vprašanje o tem, kako dolgo bodo nacionalne vojske še eden pomembnih srebrov nacionalnovarnostne strukture. Ker se radikalne spremembe družbenih, ekonomskih in političnih odnosov imenujejo revolucije, je nastalo vprašanje, ali bo nova paradigma tudi revolucionarna in poimenovana revolucija. Dodajmo ugotovitev, da je transformacijska paradigma odziv na revolucijo na vojaškem področju v informacijski dobi. V podobnem kontekstu se kot antipod spreminjanju nacionalnih držav z revolucijami ali vojnami pojavlja tudi ideja o njihovi nenasilni preobrazbi. 


\subsection{O revolucijah na vojaškem področju in transformaciji}

Najprej omenimo, da na področju tako imenovane revolucije na vojaškem področju srečamo pojava vojaška revolucija (angl. Military Revolution - MR) in revolucija v vojaških zadevah (angl. Revolution in Military Affairs - RMA). Prvi je v strokovnih obravnavah prevladoval od petdesetih do sedemdesetih let prejšnjega stoletja, drugi pa od sedemdesetih naprej in kaže, da je prvega nekako nadomestil, čeprav so med njima razlike.

Proučevanje prvega pojava pokaže, da so se razprave o vojaški revoluciji začele $\mathrm{v}$ petdesetih letih prejšnjega stoletja ${ }^{7}$, ko je bila hladna vojna že $\mathrm{v}$ zagonu in je pomembno usmerjala družbeni in zlasti ekonomski razvoj. Izraz vojaška revolucija je povezan pretežno s tehnologijo in spremembami, ki jih ta prinaša. Za njegovo utemeljitev je treba poseči po zgodovinskih metodah in študijah tehnoloških vojaških dosežkov in inovacij ter njihovih vplivov. Downing (1992) in Parker (1996) sta pri tem v svojih ugotovitvah izpostavljala stališča o vlogi vojaške tehnologije kot ključnega dejavnika ter o njenih vplivih na (geo)politiko in družbo. Tako sta se pojem in teorija vojaške revolucije s prvotne domene tehnoloških sprememb in vplivov na vojskovanje razširila in se zelo približala pojavu, ki se imenuje revolucija v vojaških zadevah.

Pojem in teorija o revoluciji v vojaških zadevah (RMA) se pojavita, ko v sedemdesetih letih prejšnjega stoletja ZDA preusmerijo svojo strateško pozornost z indo-kitajskega območja nazaj na Evropo in se razvije koncept zračno-kopenske bitke (angl. Air Land Battle - ALB) (Rizwan, 2000). Zanimivo je (Baylis in drugi, 2004, str. 242-248), da je bil leta 1984 pobudnik teorije maršal Nikolaj Vasiljević Ogarkov, načelnik sovjetskega generalštaba (1977-1984), razvili pa so jo na drugi strani takratnih vojaških blokov, in sicer svetovalec Andrew Marshall in njegovi sodelavci v Pentagonu ${ }^{8}$. RMA se pojavlja kot teorija o prihodnosti bojevanja, temelječa na tehnoloških in organizacijskih ter strateških izhodiščih, pa tudi kot koncept, ki ga poleg ZDA uvajajo v več drugih državah, članicah Nata (Rizwan, 2000). Kot ugotavljajo Baylis in drugi (2004, str. 243), se pri tem izpostavlja dominantna vloga tehničnega dejavnika, ki ima prevladujoč vpliv na vse druge v vojskovanju. Danes RMA pogosto omenjajo v povezavi s peto dimenzijo bojevanja, v kateri se poleg kopenske, morske, zračne in vesoljske pojavlja še informacijska komponenta (Gray, 2004; Gongora in Riekhoff, 2000; Barnett, 2004; in drugi).

Nekateri RMA enačijo s transformacijo ali zagovarjajo, da je transformacija v bistvu nadaljevanje teorije RMA, medtem ko drugi to dvoje ločujejo oziroma zavračajo. Vprašanje, ali gre pri transformaciji za nadaljevanje revolucije v vojaških zadevah ali zgolj za vzpostavljanje ravnotežja v razvoju, pa je zanimivo tudi za našo obravnavo. O tem zanimivo primerjavo daje Hundley (1999), ko išče odgovore o tem, kaj lahko

\footnotetext{
Izraz se je pojavil leta 1955, ko je Michael Roberts proučeval zgodovinske spremembe v artileriji in primerjal to z dogajanji v moderni vojaški zgodovini na področju vojaških zadev, kar je predstavil na predavanju na Univerzi v Belfastu in zatem leta 1956 publiciral v javnosti (Rogers, 1995, 1. pogl.).

8 O stičnih točkah in predvsem razlikah med sovjetskim in ameriškim pogledom v razpravi Adamsky (2008).
} 
zgodovina RMA pove o transformaciji vojstva. Nov ameriški koncept, tako Hundley (1999, str. xxii), se pojavi v Strateškem obrambnem pregledu iz leta 1997, v katerem je prvič predvidena transformacija in so postavljeni cilji zanjo.

\subsection{Revolucijski oziroma evolucijski značaj transformacije}

V ospredju naše razprave je že omenjena dilema, ali gre pri transformaciji za revolucijo oziroma evolucijo. V čem je razlika, zakaj trditi, da je transformacijska paradigma bolj evolucijska kot revolucijska. Za odgovor na vprašanje, ali je transformacija nova revolucijska ali zgolj kompleksna evolucijska sprememba, je treba upoštevati temeljne značilnosti transformacijske paradigme. Pri transformaciji gre za premišljeno in nenasilno, na znanju temelječe globalno spreminjanje, ki prinaša novo obliko in novo poslanstvo. Pri tem, to je treba posebej izpostaviti, pa prihaja do spremembe kompetenc nekega dominantnega nosilca in oblikovanja novih nosilcev in kompetenc.

Po Handleyevih (1999) opisih značilnosti RMA bi sklepali, da je odgovor na vprašanje odvisen predvsem od dominantnega nosilca, njegove vloge in smotra uporabe. Dominantni nosilec pa so vojaške strukture znotraj obrambnih sistemov nacionalnih držav. Ima torej transformacija na področju obrambno-vojaških sistemov več revolucijskih kot evolucijskih značilnosti? V preteklosti so temeljite in predvsem radikalne spremembe označevali z revolucionarnimi, v transformacijskem obdobju pa so označene kot evolucijske ravno zaradi dominantnih nosilcev - nacionalnih držav in njihovih obrambno-vojaških sistemov, ki ohranjajo svoj položaj in vlogo, čeprav se radikalno spreminjajo.

Del odgovora je tudi v tem, da gre pri transformacijskem spreminjanju za prostovoljno spreminjanje, temelječe na znanju in različnih inovacijah, ki se dotika vseh sestavin strukture, njenega poslanstva in delovanja ter posledično tudi socialnega ter funkcionalnega imperativa in kulture obrambno-vojaških organizacij. Vse to pa se povezuje tudi navzven, z okoljem in sodelujočimi družbenimi sistemi.

$\mathrm{K}$ temu je pri transformaciji treba dodati še nekaj drugih, imenujmo jih sodobnih organizacijskih izzivov, od katerih je na prvem mestu izziv, kako izboljšati stroškovno učinkovitost in racionalizacijo obrambno-vojaških sistemov, pa tudi izziv, povezan $\mathrm{z}$ nenehnim izboljševanjem vizije o vodenju vojn in bojevanju ter z organizacijsko klimo sodobnih vojaških organizacij (Handley, 1999, str. 55). Ta vedno pogosteje vključuje tudi tako imenovano pozitivno organizacijsko klimo (prav tam) in s tem nastajajočo sinergijo za spremembe. Te ugotovitve kažejo na posebnost transformacijske paradigme, ki na premišljen in nenasilen način uveljavlja nekatere nove kompetence in njihove nosilce ter tako postopno vpliva tudi na spreminjanje vojaške organizacije kot globalnega nosilca kompetenc. Celovitost, premišljenost in proces sprememb govorijo v prid njihovi evolucijski naravi.

Temeljna razlika med revolucionarno in transformacijsko paradigmo je $\mathrm{v}$ odnosu do vloge nasilja in kaosa ter $\mathrm{v}$ posledicah za subjekte sprememb. Gre v bistvu 
za izhodiščne razlike med revolucionarnim in evolucijskim naukom oziroma paradigmo. Revolucionarna paradigma, ki prav tako vodi v preobrazbo, temelji na uničenju starega in s tem na ustvarjanju prostora za novo in novega nosilca. Pri transformaciji pa gre za opustitev starih vzorcev oziroma za njihovo preobrazbo. Tudi zato se transformacija sklicuje na znanje, tehnologijo, sinergijo in načrtnost. S tega zornega kota je transformacija časovno zahtevnejša. Tu pa je še ena, v nekaterih pogledih zelo pomembna razlika oziroma značilnost. Revolucije se praviloma zgodijo na neki kritični točki, ko se ustvari zadostna kritična masa in energija za hitre spremembe, ki so po naravi nasilne, ali pa to nadomešča pritisk za hitro in radikalno spremembo. Podlaga za kritično točko revolucionarnih sprememb je lahko tudi kaos ali kriza v delovanju ali funkcioniranju. Hitri in radikalni revolucionarni spremembi sledi obdobje revolucionarne stabilizacije ali utrditve. Pri transformacijah se kot predhodniki pojavljajo tranzicijska oziroma prehodna obdobja, ki vodijo do transformacijskih sprememb. Ta so daljša, pa tudi bolj negotova $\mathrm{v}$ pogledu doseganja končnega cilja. Po naravi transformacijske spremembe niso nič manj radikalne, imajo pa drugačne posledice za subjekte. Zato bi revolucionarno spreminjanje lahko označili s hitrim uničenjem starega in postopnim vzpostavljanjem novega, transformacijsko spreminjanje pa s postopnim opuščanjem starega in načrtnim vzpostavljanjem novega. Transformacijo je na mikro ravni treba ne le razumeti, temveč ustvariti tudi klimo ter sinergijo za spremembe. S tem je transformacija na videz v težjem položaju, kot so spremembe revolucionarne narave, ki jih navadno v razmerah neizogibnosti sprememb poganjata vodilna elita in revolucionarni zagon.

Omeniti je treba še, da revolucija na vojaškem področju razlaga vplive razvoja vojaške tehnologije v obdobjih industrijskega razvoja in industrijske revolucije, medtem ko so $\mathrm{s}$ transformacijo zajete spremembe $\mathrm{v}$ informacijskem obdobju in razvoju digitalizacije. Poleg tega transformacija ne temelji na podmeni, da je njena preobrazba na obrambno-vojaškem področju tista, ki dominantno povzroča druge spremembe, temveč, da so spremenjene okoliščine tiste, katerim se obrambno-vojaški sistemi, tako kot drugi družbeni sistemi, celovito prilagajajo in se, ne nazadnje, transformirajo.

V obdobju globalizacije pa smo pri opredeljevanju transformacijskih značilnosti še pri dveh posebnostih, prvič pri vplivu na širše družbeno okolje in mednarodne organizacije ter drugič pri globalni klimi za spremembe. Zapisano drugače, še vedno je odprto vprašanje, ali je mogoče preobrazbo sveta doseči z revolucijo 9 . Nekateri ideološki poskusi, kot na primer komunizem kot svetovni proces, niso uspeli. Huntingtona v delu o spopadu civilizacij skrbi, ali bi ta v prihodnje potekal na civilizacijski oziroma religiozni podlagi. Nasprotniki revolucij pa bi dejali, da je dovolj revolucij, ker je čas za transformacijo.

\footnotetext{
9 Potts in Thachary (2005, str. 10-29) v poglavju s pomenljivim naslovom: No Revolution Please, We are British, utemeljujeta, zakaj ideje francoske revolucije niso uspele v Britaniji. Obenem odgovarjata na vprašanje, kako je treba gledati na, po njunem sedanje RMA v informacijski dobi-bolj evolucijsko kot revolucionarno, in pri tem izhajata iz tako imenovanega Yettonovega modela revolucionarnih sprememb v vojaških zmogljivostih.
} 
Sklep Ponovimo ugotovitev, da transformacija združuje značilnosti tako revolucionarnega kot evolucijskega spreminjanja. V razpravi smo navedli, na katerih točkah transformacija predstavlja evolucijsko spreminjanje in se v tem pogledu razlikuje od revolucionarnega. Pri tem sta pristop in časovna dimenzija bolj evolucijska. Revolucionarne značilnosti pa se kažejo, ko transformacija vodi v spreminjanje nacionalnovarnostnih sistemov in izginjanje nacionalnih vojsk $\mathrm{v}$ večnacionalnih sestavah ali obrambno-vojaških sistemih, kar vodi k spreminjanju globalnih nosilcev kompetenc: nacionalne države, obrambno-vojaškega sistema in vojske znotraj njega. $\mathrm{Na}$ tej točki transformacija kot proces in paradigma trči v prej omenjene globalne nosilce kompetenc. S spreminjanjem kompetenc nekega dominantnega nosilca in oblikovanjem novih nosilcev in kompetenc se spremembe, revolucionarne po značaju, vzpostavljajo na nov način. Na zunaj je transformacija le ena izmed oblik spreminjanja obrambnih sistemov in vojsk znotraj njih, vendar sodobniki v tem procesu vidijo pomembnejši premik, kot odziv na globalizacijo. Pri tem je nedvoumno, da je transformacija primer za iskanje univerzalnejšega modela preobrazbe obrambno-varnostnih sistemov v obdobju globalizacije.

\section{Literatura}

1. Adamsky, D., 2008. "Through the Looking Glass: The Soviet Military-Technical Revolution and the American Revolution in Military Affair". http://www.tandfonline.com/ doi/pdf/10.1080/01402390801940443 (6. maj 2015).

2. Alberts, D. S., 2003. Information Age Transformation: getting to a $21^{\text {st }}$ Century Military. Washington D.C: CCRP Publication Series.

3. Alberts, D. S., in Richard E. H., 2005. Campaigns of experimentation: pathways to innovation and transformation. Washington D.C.: CCRP Publication.

4. Alberts, D. S., John J. G., Richard E. H., in David T. S., 2004. Understanding Information Age Warfare. Washington D.C.: CCRP Publication.

5. Barnett, T. P. M., 2004. The Pentagon's New Map: War and Peace in the Twenty-first Century. New York: G.P. Putnam's sons.

6. Baylis, J., Wirtz., C. E. in Colin S. G., 2004. Strategy in the Contemporary World: An Introduction to Strategic Studies. New York: Oxford University Press.

7. Binnendijk, H. in Johnson, S. E., ur., 2004. Transforming for Stabilization and Reconstruction Operations. Washington D.C: National Defense University Press.

8. Binnendijk, H. in Kugler, R. L., ur., 2006. Seeing the Elephant: The U.S. Role in Global Security. Washington D.C: National Defense University Press \& Potomac Books, Inc.

9. Binnendijk, H., ur., 2002. Transforming America's Military. Washington D.C.: National Defense University Press.

10. Brinc, D., Derman-Zadravec, T., Furlan, B. in Hafner, T., 2006. Angleško-slovenski vojaški terminološki slovar. Ljubljana: PDRIU.

11. Brožič, L., 2013. Transformacija oboroženih sil. Revija obramba 45 (2): 4-6.

12. Cambridge University Press, 2008. Cambridge Advanced Learner's Dictionary (CALD) Third edition. Lavis-Trento: Lego Print S.p.A.

13. DOD US, Office of Force Transformation, 2003. Military Transformation: A Strategic Approach. Washington D.C.: Office of the Force Transformation.

14. Dolinar, D., ur., 1994. Leksikon Cankarjeve založbe: 3. izdaja. Ljubljana: CZ.

15. Downing, Brian M., 1992. The Military Revolution and Political Change: Origins of Democracy and Autocracy in Early Modern Europe. New Jersey: Princeton University Press.

16. Furlan, B., Rečnik, D., Vrabič, R., Maraš, V., Cerkovnik, J., Špur, B., Šonc, M., Tušak, M., Ivanuša, M., Gorjup, B., Kojadin, M., Lasič, K., Unger, M., 2006. Vojaška doktrina. Ljubljana: Defensor. 
17. Thierry, G. in Riekhoff, H., ur., 2000. Toward a Revolution in Military Affairs? Defense and Security at the Dawn of the Twenty-First Century. Westport, CT: Greenwood Press.

18. Gray, C. S., 2004. Strategy for Chaos: Revolutions in Military Affairs and the Evidence of History. London: Frank Cass.

19. Grizold, A., 2005. Slovenija v spremenjenem varnostnem okolju: $k$ razvoju obrambno-zaščitnega sistema: izzivi in spodbude. V Varnostne študije, 81-140. Ljubljana: FDV.

20. Hammer, M., in Champy, J., 1993. Reengineering the Corporation: A Manifesto for Business Revolution. London: Harper Collins.

21. Hundley, R. O., 1999. Past Revolutions, Future Transformations. Santa Monica: Rand.

22. Ibrügger, L., 1998. The Revolution in Military Affairs-Special Report. Nato Parliamentary Assembly Science and Technology Committee. http://www.iwar.org.uk/rma/ resources/nato/ar299stc-e.html (6. maj 2015).

23. Jasper, S., ur., 2009. Transforming Defense Capabilities. London: Lynne Rienner Publishers.

24. Jelušič, L., in Kopač, E., ur., 2006. Obrambna industrija v Evropski uniji: izzivi in priložnosti za Slovenijo. Ljubljana: Obramboslovni raziskovalni center.

25. Jelušič, L., 2002a. Continuity, restructuring, or development from scratch? Dilemmas of Slovenian defense reform 1991-2001.V Post-Cold War defense reforms: lessons learned in Europe and the United States, 111-134. Washington D.C.: Brassey's.

26. Jelušič, L., 2002b. Konverzija vojaštva: perspektive uporabe po koncu hladne vojne. V Politični procesi in institucije, 149-169. Ljubljana: FDV.

27. Jelušič, L., 2005. Military reforms in Slovenia. V The European armed forces in transition: a comparative analysis, 129-144. New York: Peter Lang.

28. Kaplan, R. S., in Norton, D. P., 2001. The Strategy focused organization. Boston: Harvard Business School Publishing Press.

29. Knott, S. W., 2004. "Knowledge Must Become Capability”: Institutional Intellectualism as an Agent for Military Transformation. V Essays 2004: Chairman of Joint Chiefs of Staff Strategy Essay Competition, 39-56. Washington D.C.: National Defense University Press.

30. Kopač, E., 2006. Globalizacija obrambne industrije: rekonstrukcija evropskih in ameriških obrambnih podjetij. V Demokracija v globalizaciji, globalizacija v demokraciji, 109-124. Ljubljana: Fakulteta za družbene vede.

31. Korošec, T., ur., 2002. Vojaški slovar: Predelana in dopolnjena izdaja. Ljubljana: Delo.

32. Kovač, J., ur., 1999. Sodobne oblike in pristopi pri organiziranju podjetij in drugih organizacij. Kranj: Moderna organizacija.

33. Kožar, J.j D., 2007. Zbornik člankov, referatov in študij: Z obrambo do varnosti. Kotlje: Samozaložba J. D. Kožar.

34. Law, D., 2009. DCAF Backgrounders - Defense reform. http://www.dcaf.ch/Publications/ Defence-Reform (6. maj 2015).

35. Lipovec, F., 1987. Razvita teorija organizacije. Maribor: Založba Obzorja.

36. Mandeles, M. D., 2007. Military Transformation Past and Present: Historic Lessons for the $21^{\text {st }}$ Century. Westport, CT: Praeger Security International.

37. Manigart, P., in Jelušič, L., ur., 2001. European defence restructuring: military and public view. Brussels: European Commission.

38. Metz, S., in Kievit, J., 1995. Strategy and Revolution in Military Affairs. Carlisle: Strategic Institute.

39. Možina, S., Kavčič, B., Tavčar, M. I., Pučko, D., Ivanko, Š., Lipičnik, B., Gričar, J., Repovž, L., Vizjak, A., Vahčič, A., Rus, V., 1994. Management. Radovljica: Didakta.

40. Nato Public Diplomacy Division, 2005. Examing Nato's Transformation. Brussels: Public Diplomacy Division. http://www.nato.int/DOCU/review/2005/NATO-Transformation/EN/ index.htm (6. maj 2015). 
41. Nato Public Diplomacy Division, 2006. Nato Handbook. Brussels: Public Diplomacy Division.

42. Neal, D., Friman, H., Doughty, R. in. Wells, L. II, 2009. Crosscutting Issues in International Transformation: Interactions and Innovations among People, Organizations, Processes, and Technology. Washington D.C.: National Defense University,

43. Parker, G., 1996. The Military Revolution: Military Innovation and the Rise of the West, 1500-1800. Cambridge: Cambridge University Press.

44. Podbregar, I., 2011. Pred reinženiringom nacionalnovarnostnega sistema - priložnosti za Slovensko vojsko. Sodobni vojaški izzivi 13 (2): 15-26.

45. Potts, D., in Thackray. J., 2005. No Revolutions Please, We're British. V The Big Issue: Command and Combat in the Information Age, ur. Potts David, 29-42. Washington D.C.: CCRP Publication Series.

46. Prebilič, V., 2002. Upravljanje konverzije vojaških objektov. V Nacionalna in mednarodna varnost: iz obramboslovnih raziskav III,188-209. Ljubljana: FDV.

47. Rizwan, S., 2000. Revolution in Military Affairs (RMA). http://www.defencejournal. com/2000/sept/military.htm (6. maj 2015).

48. Rogers, C. J., ur., 1995. The Military Revolution Debate: Readings on the Military Transformation of Early Modern Europe. Boulder: Westview Press Inc.

49. Rozman, R., Kovač, J. in Koletnik, F., 1993. Management. Ljubljana: Gospodarski vestnik.

50. SAZU, 2000. Slovar slovenskega knjižnega jezika. Ljubljana. Ljubljana: DZS.

51. Selby, J., in Jelušič, L., ur., 1999. Defence restructuring and conversion: sociocultural aspects. Brussels: European Commission.

52. SIB: Sprachinstitut des Bundesheeres, 2010. Vojaški slovar-slovensko-nemški. Dunaj: ReproZ.

53. Smith, L. L., 2006. Understanding NATO Military Transformation. Norfolk, VA: ACT Multimedia Library.

54. Žnidaršič, I., 1998. Besedišče slovenskega jezika z oblikoslovnimi podatki: elektronska izdaja - 2001. Ljubljana: Državna založba Slovenije.

55. Šteiner, A., 1998. Reorganizacija Slovenske vojske. V Struktura oboroženih sil v demokraciji: simpozij 9.-12. marec 1998 Poljče: zbornik. Poljče: Ministrstvo za obrambo in Zvezno ministrstvo za obrambo Nemčije.

56. Šteiner, A., 2013. Izziv, kot ga še ni bilo, Transformacija SV. Revija. Obramba, 45 (12013): $18-20$.

57. Švab, M., in Berlogar, J., 2013. Transformacija ali preoblikovanje-terminološki kotiček. Revija Slovenska vojska (6): 45.

58. Tavzes, M., in Adlešič, G., ur., 2002. Veliki slovar tujk. Ljubljana: Cankarjeva založba.

59. Transformation of the United States Army. http://military.wikia.com/wiki/Transformation of_the_United_States_Army (6. maj 2015).

60. Verbinc, F., 1978. Slovar tujk. Ljubljana: Cankarjeva založba.

61. White Paper 2006 on German Security Policy and the Future of the Bundeswehr. Dostopno na: http://www.bmvg.de/portal/a/bmvg/!ut/p/c4/ Dca7DYAwDAXAWVgg7unYAuicYCVPQrnsz7omqObfoUnPHfUwolOuhx2u4zN0xuFC IGQddWEzqi4eLF1i7mqXFkKf-WQNUOF6jFY_sAY_7e5g!!/ (6. maj 2015). 